BMJ Open

Diabetes

Research

\& Care

\section{Analysis of the interaction effect of 48 SNPs and obesity on type 2 diabetes in Chinese Hans}

To cite: Liu J, Wang L, Qian Y, et al. Analysis of the interaction effect of 48 SNPs and obesity on type 2 diabetes in Chinese Hans. BMJ Open Diab Res Care 2020;8:e001638. doi:10.1136/ bmjdrc-2020-001638

- Supplemental material is published online only. To view, please visit the journal online (http://dx.doi.org/10.1136/ bmjdrc-2020-001638).

$\mathrm{JL}$ and $\mathrm{LW}$ are joint first authors.

Received 4 June 2020 Revised 14 September 2020 Accepted 21 September 2020

Check for updates

(C) Author(s) (or their employer(s)) 2020. Re-use permitted under CC BY-NC. No commercial re-use. See rights and permissions. Published by BMJ.

${ }^{1}$ Department of Health Promotion \& Chronic NonCommunicable Disease Control, Wuxi Center for Disease Control and Prevention, Wuxi, China ${ }^{2}$ Department of Epidemiology and Biostatistics, School of Public Health, Nanjing Medical University, Nanjing, China

Correspondence to

Dr Yun Qian;

wxqianyun111@sina.com

\section{ABSTRACT}

Introduction Both environmental and genetic factors contribute to type 2 diabetes (T2D) risk. Dozens of T2D susceptibility loci have been identified by genome-wide association study. However, these loci account for only a small fraction of the familial T2D risk. We hypothesized that the gene-obesity interaction may contribute to the missing heritability.

Research design and method Forty-eight T2Dassociated variants were genotyped using the TaqMan OpenArray Genotyping System and iPLEX Sequenom MassARRAY platform in two separate studies. Obesity was defined according to multiple indexes (body mass index (BMI), waist circumference and waist-hip ratio). Multiplicative interactions were tested using general logistic regression to assess the gene-obesity interaction effect on T2D risk among a total of 6206 Chinese Hans. Results After adjusting for the main effects of genes and obesity, as well as covariates (age, sex, smoking and alcohol consumption status), robust multiplicative interaction effects were observed between rs10811661 in CDKN2A/CDKN2B and multiple obesity indices ( $\mathrm{p}$ ranged from 0.001 to 0.043 for BMI, waist circumference and waist-hip ratio). Obese individuals with the TT genotype had a drastically higher risk of T2D than normal weight individuals without the risk allele $(0 R=17.58, p<0.001)$. There were no significant differences between subgroups in the stratification analysis. Plausible biological explanations were established using a public database. However, there were no significant interaction effects between the other 47 single nucleotide polymorphism (SNPs) and obesity.

Conclusion Our findings indicated that the CDKN2A/ $C D K N 2 B$ gene-obesity interaction significantly increases T2D risk in Chinese Hans. The interaction effect identified in our study may help to explain some of the missing heritability in the context of T2D susceptibility. In addition, the interaction effect may play a role in the precise prevention of T2D in Chinese individuals.

\section{INTRODUCTION}

Type 2 diabetes (T2D) is a common disorder characterized by hyperglycemia, insulin resistance and deficient pancreatic beta-cell function, which accounts for approximately $90 \%$ of all diabetes cases. ${ }^{1}$ According to the estimation of the International Diabetes Federation,

\section{Significance of this study \\ What is already known about this subject? \\ - The prevalence of type 2 diabetes (T2D) in China rapidly increased in recent years. Several risk fac- tors have been found including obesity and genetic variants. \\ What are the new findings? \\ - In our current research, we focused on the interac- tion effect between SNPs and obesity for T2D. We found that $C D K N 2 A / C D K N 2 B$ gene-obesity interac- tion significantly increases T2D risk in Chinese Hans. \\ How might these results change the focus of research or clinical practice? \\ - The interaction effect identified in our study may help us to explain some of the missing heritability in the context of T2D susceptibility. In addition, the interaction effect may play a role in the precise pre- vention of T2D in Chinese individuals.}

463 million adults worldwide were affected by diabetes in 2019, and this number will increase to 700 million in 2045. In addition, 4.2 million deaths worldwide were attributed to diabetes in 2019. Notably, approximately $79 \%$ of patients with diabetes live in low-income and middle-income countries including China. ${ }^{2}$ The prevalence of T2D in China rapidly increased from less than $1 \%$ in 1980 to $11.6 \%$ in $2010 .{ }^{3}$ Diabetes has become an urgent public health problem worldwide, and it is essential to understand its pathogenesis to slow down the rapidly increasing rate.

Obesity is an underlying cause of chronic noncommunicable disease, including T2D. Over the past few decades, rapid economic changes have drastically affected lifestyle and obesity rates, contributing to an epidemic of T2D. ${ }^{4}$ Approximately $90 \%$ of T2D cases are attributed to excess weight. ${ }^{5}$ Wilson et at found that obesity was a significant predictor of T2D in the prospective Framingham Offspring Study $(\mathrm{OR}=2.50, \mathrm{p}=0.001)$. These 
findings together revealed the critical role of obesity in T2D.

Genetic factors also contribute to the pathogenesis of T2D. ${ }^{1}$ T2D has an estimated rate of heritability of $30 \%-70 \% .^{7}$ Over the past several years, genome-wide association studies (GWAS) have provided new susceptibility loci for T2D. ${ }^{8-14}$ In our previous study, we successfully validated the association between single nucleotide polymorphism (SNPs) and T2D risk as well as lipid levels in Chinese Hans. ${ }^{1516}$ However, these common variants account for only a small fraction of the familial risk of T2D, with a modest effect contributed by each locus (OR for each allele ranging from 1.1 to 1.5$).{ }^{17}$

To explain the missing heritability, many hypotheses have been proposed, including gene-environment interactions. ${ }^{18}$ However, no systematic study focusing on multiple genes has been performed to evaluate the interaction between SNPs and obesity in context of T2D risk in Chinese Hans. In this current study, we attempted to evaluate the gene-environment interaction in 2925 T2D cases and 3281 matched controls in Chinese Hans.

\section{MATERIALS AND METHODS}

\section{Study subjects}

This study was approved by the Institutional Review Board of Wuxi Center for Disease Control and Prevention. The details of the study subjects have been described previously. ${ }^{19}{ }^{20}$ In brief, one part of samples (1200 T2D cases and 1200 orthoglycemic controls) were recruited from a community-based noncommunicable disease screening program conducted in Wuxi, Jiangsu, China from April to July in 2007 (Wuxi study). The other portion of samples (1725 cases and 2081 controls) were recruited from a population-based cohort study conducted in Changzhou and Nantong cities in Jiangsu Province during 2004 and 2008 (Changzhou-Nantong study). T2D cases were defined according to fasting plasma glucose $(\mathrm{FPG}) \geq 7.0 \mathrm{mmol} / \mathrm{L}$ or a history of T2D. ${ }^{21}$ Controls were selected from the subjects with FPG level $<5.6 \mathrm{mmol} / \mathrm{L}$ and without a history of diabetes, coronary heart disease, hypertension, stroke or cancer. Controls were frequently matched to the cases by age, sex and residential area. Subjects were interviewed in person by trained interviewers to collect personal information and demographic data after signing informed consent forms. Personal information including name, ID number, address, career, history of diabetes, hypertension, stroke and cancer, smoking and drinking status were collected. Physical examinations including height, weight, waist circumference (WC), hip circumference and blood pressure were performed at the same time. Body mass index (BMI) was divided based on the Chinese criteria or WHO criteria: ${ }^{21}$ Chinese criteria: underweight: $\mathrm{BMI}<18.50 \mathrm{~kg} /$ $\mathrm{m}^{2}$; normal: $18.50 \leq \mathrm{BMI}<24.00 \mathrm{~kg} / \mathrm{m}^{2}$; overweight: $24.00 \leq \mathrm{BMI}<28.00$ and obesity: $\mathrm{BMI} \geq 28.00 \mathrm{~kg} / \mathrm{m}^{2}$. Individuals were defined as smokers if they had smoked at an average of one cigarette or more per day and for at least 1 year in their lifetime. Similarly, participants were defined as drinkers if they drunk at least once per day and $\geq 4$ days per week. Approximately $5 \mathrm{~mL}$ venous blood was collected from each subject after fasting for more than 8 hours. FPG and lipid levels (triglycerides (TG), total cholesterol (TC) and high-density lipoprotein cholesterol (HDL-C)) levels were measured in a standard method by Biochemistry Auto-analyzer (Olympus C2734-Au640).

\section{SNP selection}

The details of the selection process have been described previously. ${ }^{15}$ Briefly, 76 SNPs were reported in the GWAS catalog, and we included SNPs based on the following criteria: (1) minor allele frequency $\geq 0.05$ in Chinese Han and (2) SNPs with strong linkage disequilibrium $\left(r^{2}>0.8\right)$; potential functional variants were retained as priorities. As a result, 48 SNPs from 34 genes were included in this study (online supplemental table 1 ).

\section{DNA isolation, genotyping and quality control (QC)}

Genomic DNA was isolated from the leukocyte pellets of venous blood by proteinase $\mathrm{K}$ digestion, followed by phenol-chloroform extraction and ethanol precipitation. All of the DNA samples were checked for quality by DNA electrophoresis. For the participants in Wuxi study, genotyping was performed using TaqMan OpenArray Genotyping System (Life Technologies, Carlsbad, California, USA). The overall call rates ranged from $98.5 \%$ to $99.3 \%$. For Changzhou-Nantong study, SNPs were genotyped by iPLEX Sequenom MassARRAY platform (Sequenom, San Diego, California, USA). For quality control, there were two nontemplate controls in each plate. Based on the duplicate samples, the concordance rate was $100 \%$ for this two-genotyping platform.

\section{Statistical analysis}

The distributions of continuous variables (age, BMI, FPG level, WC, hip circumference and lipid levels) were described using the mean $\pm \mathrm{SD}$ or median value $(\mathrm{P} 25$, P75). Categorical variables (sex, smoking status and alcohol consumption status) were defined as counts (percentages). Multiplicative interactions were tested using a general logistic regression model by applying the equation:

$$
Y=\beta_{0}+\beta_{G} \times G+\beta_{E} \times E+\beta_{G E} \times(G \times E)+\Sigma \beta_{i} \times \text { Covar }_{i}
$$

where $Y$ is the logit of case-control status, $G$ is the selected SNPs and $E$ is the environment factor (obesity). $\beta_{0}$ is the constant, and $\beta_{G}$ and $\beta_{E}$ represent the main effects of SNPs and obesity, respectively. $\beta_{G E}$ is the interaction term and Covar ${ }_{i}$ are the covariates for adjustment, including age, sex, smoking status and alcohol consumption status. The effect size directions of interaction should be consistent in Wuxi study and Changzhou-Nantong study for further analysis. To examine the differences between subgroups, the $\chi^{2}$-based Q-test was used to test the heterogeneity of effect sizes (ORs and 95\% CIs) derived from 
Table 1 Demographic and clinical characteristics of study subjects

\begin{tabular}{|c|c|c|c|c|c|c|}
\hline \multirow[b]{2}{*}{ Variables } & \multicolumn{2}{|l|}{ Wuxi study } & \multicolumn{2}{|c|}{ Changzhou-Nantong study } & \multicolumn{2}{|l|}{ Combined } \\
\hline & Case $(n=1200)$ & Control $(n=1200)$ & Case $(n=1725)$ & Control $(n=2081)$ & Case $(n=2925)$ & Control $(n=3281)$ \\
\hline \multicolumn{7}{|l|}{ Gender } \\
\hline Male (\%) & $478(39.83)$ & $478(39.83)$ & $620(35.94)$ & $756(36.33)$ & $1098(37.53)$ & $1234(37.61)$ \\
\hline \multicolumn{7}{|l|}{ Smoke } \\
\hline Ever (\%) & $320(26.73)$ & $279(23.37)$ & $401(23.46)$ & $548(26.55)$ & $721(24.81)$ & $827(25.38)$ \\
\hline \multicolumn{7}{|l|}{ Alcohol consumption } \\
\hline Ever (\%) & $208(17.72)$ & $128(10.73)$ & $330(19.31)$ & $507(24.60)$ & $538(18.66)$ & $635(19.51)$ \\
\hline Age (years) & $57.43 \pm 9.77$ & $56.43 \pm 8.02$ & $58.77 \pm 10.31$ & $56.66 \pm 10.81$ & $58.21 \pm 10.11$ & $56.57 \pm 9.88$ \\
\hline $\operatorname{BMl}\left(\mathrm{kg} / \mathrm{m}^{2}\right)$ & $24.92 \pm 3.42$ & $22.64 \pm 2.87$ & $25.13 \pm 3.55$ & $21.82 \pm 2.44$ & $25.05 \pm 3.50$ & $22.12 \pm 2.63$ \\
\hline Waist circumference $(\mathrm{cm})$ & $85.46 \pm 9.27$ & $81.42 \pm 9.48$ & $87.18 \pm 10.29$ & $76.08 \pm 7.96$ & $86.47 \pm 9.92$ & $78.04 \pm 8.93$ \\
\hline Hip circumference (cm) & $95.62 \pm 7.36$ & $91.21 \pm 7.93$ & $95.27 \pm 7.31$ & $90.77 \pm 6.25$ & $95.46 \pm 7.33$ & $90.99 \pm 7.16$ \\
\hline $\mathrm{FPG}(\mathrm{mmol} / \mathrm{L})$ & $8.00(6.70,10.3)$ & $4.50(4.20,4.80)$ & $8.10(7.09,10.50)$ & $4.52(4.11,4.99)$ & $8.05(7.00,10.42)$ & $4.50(4.11,4.90)$ \\
\hline $\mathrm{TG}(\mathrm{mmol} / \mathrm{L})$ & $1.77(1.22 .2 .82)$ & $1.28(0.95,1.66)$ & $1.73(1.16,3.00)$ & $0.90(0.68,1.19)$ & $1.76(1.19,2.92)$ & $1.00(0.74,1.37)$ \\
\hline $\mathrm{TC}(\mathrm{mmol} / \mathrm{L})$ & $5.29(4.58,5.98)$ & $4.62(4.14,5.15)$ & $4.60(3.91,5.26)$ & $4.21(3.70,4.80)$ & $4.86(4.17,5.62)$ & $4.39(3.85,4.95)$ \\
\hline $\mathrm{HDL}-\mathrm{C}(\mathrm{mmol} / \mathrm{L})$ & $1.36(1.15,1.56)$ & $1.48(1.29,1.71)$ & $1.44(1.21,1.73)$ & $1.63(1.40,1.88)$ & $1.40(1.19,1.65)$ & $1.57(1.35,1.83)$ \\
\hline
\end{tabular}

Data are expressed as number (per cent), mean \pm SD or median value (P25, P75).

BMI, body mass index; FPG, fasting plasma glucose; HDL-C, high-density lipoprotein cholesterol; TC, total cholesterol; TG, triglycerides.

the corresponding subgroups. All of the statistical analyses were performed with $\mathrm{R}$ software (V.3.5.1; The $\mathrm{R}$ Foundation for Statistical Computing, http://www.cran. r-project.org/) and Stata V.12.0 software (Stata, College Station, Texas, USA).

\section{RESULTS}

The demographic and clinical characteristics of study population are summarized in table 1. No significant differences of sex, smoking status and alcohol consumption status were observed in either group or the combined population $(p>0.05)$. The age of the T2D case group was approximately 1 year older than that of the control group, although the age group ( 5 years) was matched for the case and control groups. As expected, patients with T2D had significantly higher obesity indexes (BMI, WC, hip circumference), FPG, TGs and TC and lower levels of HDL-C than the control group in the combined population and the two separate groups.

The associations results between selected SNPs, obesity indices and T2D risk are shown in online supplemental table 2. First, we focused on the effect of the interaction between selected SNPs and BMI level on T2D risk. Of the 48 selected SNPs, multiplicative interaction analysis revealed that the interaction effect directions of seven SNPs were consistent in Wuxi study and ChangzhouNantong study. As shown in table 2, of these seven SNPs, rs10811661 in $C D K N 2 A / C D K N 2 B$ had a significant interaction effect with BMI level on T2D risk $(p<0.05)$. Of interest, effects of the interactions between rs10811661 and BMI level were significant in both studies (Wuxi study: $\mathrm{OR}=1.22, \mathrm{p}=0.033$; Changzhou-Nantong study:

Table 2 Interaction between selected SNPs and BMI levels on T2D risk

\begin{tabular}{|c|c|c|c|c|c|c|c|c|c|c|}
\hline \multirow[b]{2}{*}{ Gene } & \multirow[b]{2}{*}{ SNP } & \multirow[b]{2}{*}{ Allele* } & \multirow[b]{2}{*}{ MAF } & \multicolumn{2}{|c|}{ Wuxi study } & \multicolumn{2}{|c|}{$\begin{array}{l}\text { Changzhou-Nantong } \\
\text { study }\end{array}$} & \multicolumn{3}{|l|}{ Combined } \\
\hline & & & & ORt & $P$ valuet & ORT & $\mathrm{P}$ valuet & OR $(95 \% \mathrm{Cl}) \dagger$ & P valuet & FDR-P \\
\hline CDKN2A/CDKN2B & rs 10811661 & $\mathrm{~T} / \mathrm{C}$ & 0.487 & 1.22 & 0.033 & 1.21 & 0.035 & 1.22 (1.07 to 1.39$)$ & 0.003 & 0.021 \\
\hline CENTD2 & rs1552224 & $\mathrm{A} / \mathrm{C}$ & 0.087 & 1.08 & 0.626 & 1.52 & 0.018 & 1.23 (0.97 to 1.55$)$ & 0.084 & 0.196 \\
\hline KCNQ1 & rs2237892 & $\mathrm{C} / \mathrm{T}$ & 0.341 & 1.02 & 0.822 & 1.12 & 0.250 & 1.06 (0.92 to 1.21$)$ & 0.430 & 0.502 \\
\hline KCNQ1 & rs2237895 & $\mathrm{A} / \mathrm{C}$ & 0.312 & 0.94 & 0.555 & 0.82 & 0.035 & 0.88 (0.77 to 1.01$)$ & 0.061 & 0.196 \\
\hline SLC30A8 & rs13266634 & $\mathrm{C} / \mathrm{T}$ & 0.445 & 1.10 & 0.312 & 1.02 & 0.855 & 1.03 (0.91 to 1.17$)$ & 0.615 & 0.615 \\
\hline TP53INP1 & rs896854 & $\mathrm{C} / \mathrm{T}$ & 0.347 & 1.16 & 0.120 & 1.20 & 0.068 & $1.18(0.97$ to 1.25$)$ & 0.153 & 0.262 \\
\hline VEGFA & rs9472138 & $\mathrm{C} / \mathrm{T}$ & 0.110 & 0.84 & 0.203 & 0.94 & 0.679 & 0.88 (0.73 to 1.06$)$ & 0.187 & 0.262 \\
\hline
\end{tabular}

*Major/Minor allele.

†OR and $\mathrm{p}$ value were calculated by multiplicative interaction logistic regression with adjustment of SNP, BMI, age, sex, smoking and alcohol consumption.

BMI, body mass index; FDR-P, false discovery rate P value; MAF, minor allele frequency; SNP, single nucleotide polymorphism; T2D, type 2 diabetes. 
Table 3 Interaction between rs10811661 and BMI level on T2D risk

\begin{tabular}{|c|c|c|c|c|c|}
\hline BMI* $^{*}$ & Genotype & Case N (\%) & Control N (\%) & OR $(95 \% \mathrm{Cl}) \dagger$ & $\mathbf{P}$ value† \\
\hline$<18.50$ & $\mathrm{CC}$ & $9(0.31 \%)$ & $36(1.10 \%)$ & 0.80 (0.38 to 1.70$)$ & 0.565 \\
\hline $18.50-24.99$ & $\mathrm{CC}$ & $171(5.93 \%)$ & $575(17.65 \%)$ & 1 & - \\
\hline 25.00-27.99 & $\mathrm{CC}$ & $236(8.19 \%)$ & $138(4.24 \%)$ & 5.67 (4.31 to 7.46$)$ & $<0.001$ \\
\hline$\geq 28$ & $\mathrm{CC}$ & $102(3.54 \%)$ & $19(0.58 \%)$ & 18.43 (10.95 to 31.02$)$ & $<0.001$ \\
\hline$<18.50$ & $\mathrm{TC}$ & $35(1.21 \%)$ & $85(2.61 \%)$ & 1.41 (0.91 to 2.18$)$ & 0.12 \\
\hline $18.50-24.99$ & $\mathrm{TC}$ & $519(18.01 \%)$ & $1238(38.00 \%)$ & 1.42 (1.16 to 1.73$)$ & 0.001 \\
\hline 25.00-27.99 & $\mathrm{TC}$ & $628(21.79 \%)$ & $263(8.07 \%)$ & 8.13 (6.49 to 10.19$)$ & $<0.001$ \\
\hline$\geq 28$ & $\mathrm{TC}$ & $294(10.20 \%)$ & $47(1.44 \%)$ & 22.01 (15.37 to 31.51$)$ & $<0.001$ \\
\hline$<18.50$ & TT & $23(0.80 \%)$ & $62(1.90 \%)$ & 1.21 (0.72 to 2.02$)$ & 0.467 \\
\hline $18.50-24.99$ & $\mathrm{TT}$ & 364 (12.63\%) & $612(18.78 \%)$ & 1.98 (1.60 to 2.46$)$ & $<0.001$ \\
\hline $25.00-27.99$ & $\mathrm{TT}$ & $352(12.21 \%)$ & $153(4.70 \%)$ & 7.51 (5.80 to 9.71$)$ & $<0.001$ \\
\hline$\geq 28$ & TT & $149(5.18 \%)$ & $30(0.93 \%)$ & 17.58 (11.38 to 27.16$)$ & $<0.001$ \\
\hline \multicolumn{5}{|c|}{$\mathrm{P}$ for multiplicative interaction } & 0.003 \\
\hline
\end{tabular}

*BMI was divided into four groups based on Chinese criterion: underweight: <18.50; normal: 18.50-23.99; overweight: 24.00-27.99; obesity: $\geq 28.00$.

†OR and $p$ value were calculated by multiplicative interaction logistic regression with adjustment of rs10811661, BMI, age, sex, smoking and alcohol consumption.

BMI, body mass index; T2D, type 2 diabetes.

$\mathrm{OR}=1.21, \mathrm{p}=0.035$ ). After false discovery rate (FDR) correction, rs10811661 still had a significant interaction effect with BMI level on T2D risk in the combined population $(\mathrm{OR}=1.22, \mathrm{p}=0.021)$. Besides, in consideration of the small number of obesity, we combined the overweight and obesity group to conduct a sensitive analysis. The sensitive analysis showed that the interaction effect was robust $(\mathrm{OR}=1.27, \mathrm{p}=0.002)$. However, there were no significant interaction effects between the other SNPs and BMI on T2D risk (online supplemental table 1).

Compared with normal weight individuals without risk allele $\mathrm{T}$, obese individuals with the TT genotype had a substantially increased risk of T2D $(\mathrm{OR}=17.58, \mathrm{p}<0.001)$ (table 3).

We further analyzed the interaction effect between rs10811661 and other obesity indices (WC and waist-hip ratio (WHR)) on T2D risk. As shown in online supplemental tables 3 and 4, significant interaction effects were also observed between rs10811661 and other obesity indices (for WC, $\mathrm{p}=0.001$; for WHR, $\mathrm{p}=0.043$ ).

In the stratification analysis, the interaction effect was evaluated in subgroups based on age, sex, smoking status and alcohol consumption status. As shown in figure 1, there were no significant differences between subgroups in regard to the interaction effect between rs10811661 and BMI level (all $P$ for heterogeneity $>0.05$ ).

To reveal the biological role of the identified SNP, we performed a bioinformatic analysis of the results above by using the public database GTEX (http:/ /www.gtexportal. org/home/). According to GTEX database, rs10811661 in $C D K N 2 A / C D K N 2 B$ significantly decreased the expression of $C D K N 2 B$ in whole blood samples $(\beta=-0.12$, $\mathrm{p}=0.016)$ and pancreas $(\beta=-0.17, \mathrm{p}=0.035)$ (figure 2).
However, there was no significant association between rs10811661 and CDKN2A (data not shown).

\section{DISCUSSION}

In this study, we evaluated the effect of the interaction between 48 selected SNPs and obesity indexes on T2D risk in Han Chinese individuals. Robust interaction effects were observed between rs10811661 and BMI (Chinese criterion and WHO criterion), WC and WHR. To the best of our knowledge, this is the first study to report the effects of the interaction between rs10811661 in $C D K N 2 A / C D K N 2 B$ and different obesity indexes in Han Chinese individuals. Our study provided genetic

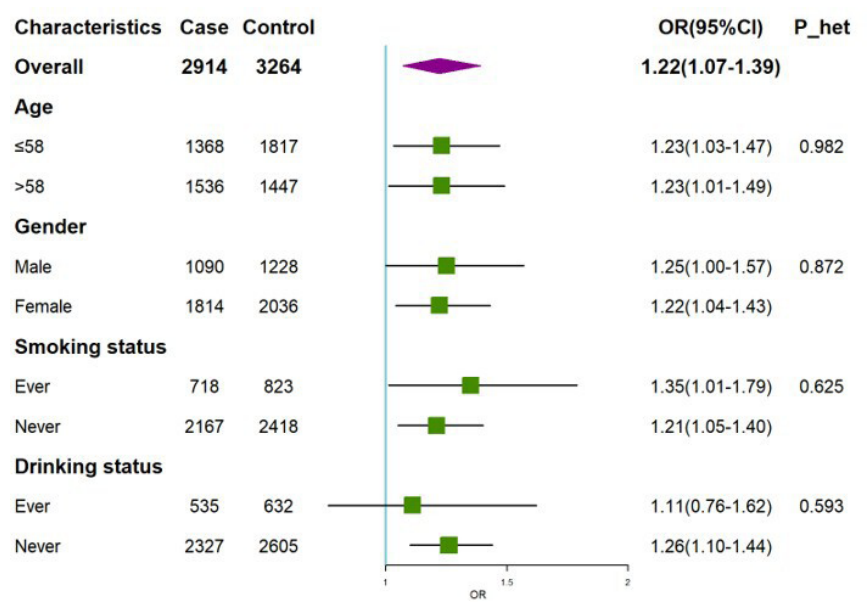

Figure 1 Stratified analysis of the interaction between rs10811661 and BMI on type 2 diabetes risk. BMI, body mass index. 


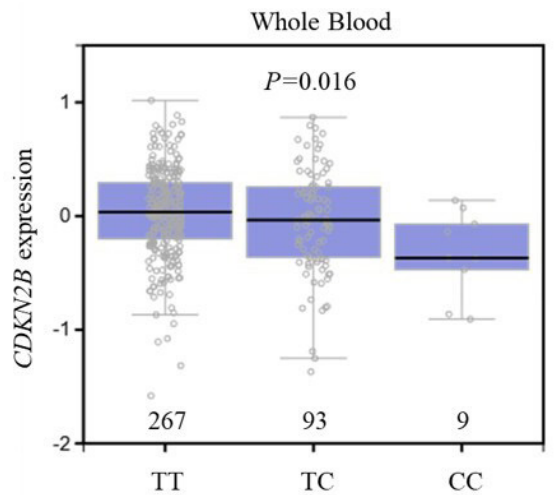

(A)

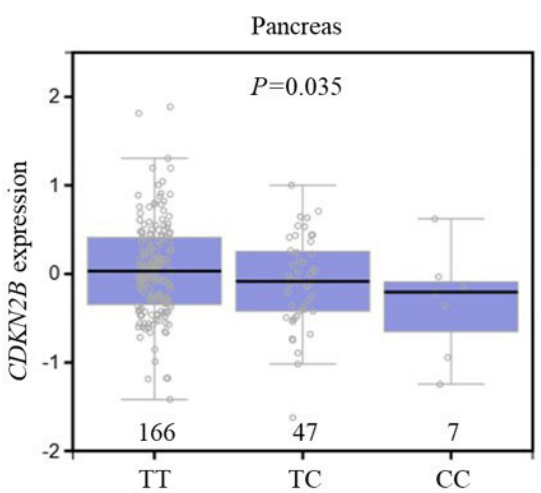

(B)

Figure 2 The association of rs10811661 with host gene expression. Data were available in public database GTEX (A: whole blood; B: pancreas).

evidence at the population level that the gene-obesity interaction may contribute to T2D risk.

Several studies have focused on the interaction effects of SNPs and obesity on T2D risk. ${ }^{22-24}$ However, these studies each mainly focused on only one gene (PPARG, FOXO1, TCF7L2), and the number of selected SNPs was limited. In addition, no research has been reported on the $C D K N 2 A / C D K N 2 B$-obesity interaction.

The SNP rs10811661 is located upstream of CDKN2A/ $C D K N 2 B$ (cyclin-dependent kinase inhibitor 2A/2B). The effect of rs10811661 on T2D risk is well known. Li et $a l^{25}$ performed a meta-analysis including 17 studies with 29990 cases and 40977 controls to evaluate the association between rs10811661 and T2D risk. The results showed that the rs10811661 $\mathrm{T}$ allele was significantly associated with increased T2D risk in the additive model $(\mathrm{OR}=1.51,95 \%$ CI 1.40 to $1.63, \mathrm{p}<0.001)$. In our previous study, a similar result was identified $(\mathrm{OR}=1.32,95 \%$ CI 1.17 to $\left.1.49, \mathrm{p}=1.22 \times 10^{-5}\right){ }^{15}$ Interestingly, in human populations, the rs10811661 risk allele $\mathrm{T}$ is also associated with reduced insulin secretory capacity. ${ }^{26-28}$

According to the GTEX database, rs10811661 is an eQTL (expression quantitative trait loci) for CDKN2B. The risk allele $\mathrm{T}$ was identified to be associated with increased $C D K N 2 B$ levels in whole blood and pancreas samples. Proteins encoded by the $C D K N 2 B$ gene regulate pancreatic beta cell replication by inhibiting cyclindependent kinase $4 / 6(\mathrm{CDK} 4 / 6) \cdot{ }^{29}$ It has been shown that mice lacking CDK4 exhibit insulin-deficient diabetes due to a reduction in pancreatic beta cells. ${ }^{30}$ These results together suggest that rs10811661 may increase the risk of T2D by affecting pancreatic beta cells. Recently, Kong et $a l^{31}$ found that the risk allele of rs10811661 increased ANRIL expression in islet samples, which correlates with higher BMI and fat mass. ${ }^{32-35}$ Obesity is well studied and has been shown to contribute to T2D risk mainly by reducing insulin sensitivity and promoting insulin resistance. ${ }^{36}$ These mechanisms may together elucidate the increased risk of T2D in obese individuals with the rs10811661 TT genotype.
BMI is usually used to assess general obesity. However, general obesity, as defined by BMI, is not a fitness indicator of body fat distribution. ${ }^{37}$ Recently, central obesity, also known as abdominal obesity, measured by WC and WHR have been widely studied. ${ }^{38}$ Cheng et $a \vec{l}^{39}$ found that WHR was a better index than BMI for predicting the risk of T2D in Taiwanese population. Besides, $\mathrm{Hu}$ et $a t^{40}$ conducted the interASIA study and found that central obesity is more related to T2D than overall obesity in the Chinese population. However, in our study, the interaction effects between SNP and general obesity, central obesity were similar (ORs for BMI, WC and WHR were 1.22, 1.31 and 1.20, respectively). There was no significant difference between these obesity indices ( $\mathrm{p}$ for heterogeneity was 0.84 ). Li $e t a t^{24}$ conducted a study to explore the interaction effect of TCF7L2 and BMI/ WC on T2D. The effect was similar for BMI and WC (for BMI: $\mathrm{OR}=4.833$; WC: $\mathrm{OR}=4.629)$. The present study is not sufficiently large to support the hypothesis that there may be difference of interaction effect between SNP-general obesity and SNP-central obesity. Further research, which focus on the difference, should be done.

There were several strengths in our present study. First, this study was well designed and included two separate study populations to ensure the authenticity of the results. Second, multiple obesity indexes were evaluated for interaction effects to ensure the robustness of the study results. Third, a public database was used, and plausible interpretations of our population results were established. However, the biological mechanisms of the identified interaction effect remain unclear. Future functional studies will be necessary to validate our findings.

In summary, our results suggested, for the first time, that rs10811661 in $C D K N 2 A / C D K N 2 B$ had robust interaction effects with multiple obesity indexes. The identified gene-obesity interaction may contribute to some of the missing heritability of $\mathrm{T} 2 \mathrm{D}$ risk.

Acknowledgements The authors wish to thank all of the study participants, research staff and students who participated in this work. We thank the GTEX Projects for making the data public. 
Contributors YQ designed and directed this study. JL and LW conducted the genotype assay and wrote this paper. QS, HM and CS directed the survey and quality control. HC and JD analyzed the data. GJ, ZH and HS directed the assay and quality control.

Funding This work was funded by the Wuxi Key Medical Disciplines grant (ZDXK010), the Wuxi Key Medical Talents grant (ZDRC004), Wuxi Young Medical Talents grant (QNRC050) for 'Strengthening Health though Science and Education', the important project of Wuxi Health Commission (Z201905), the Project of Nationa Natural Science Foundation of China (81072379), the Jiangsu scientific research project of top health talents (LGY2018014), the Wuxi science and technology development fund project (WX18IIAN038) and the Wuxi Health Commission Youth Foundation (Q201802).

Competing interests None declared.

Patient consent for publication Not required.

Ethics approval This study was approved by the Institutional Review Board of Wuxi Center for Disease Control and Prevention (approval ID: 2011(001)).

Provenance and peer review Not commissioned; externally peer reviewed.

Data availability statement Data are available on reasonable request. Data is available upon reasonable request from corresponding author.

Supplemental material This content has been supplied by the author(s). It has not been vetted by BMJ Publishing Group Limited (BMJ) and may not have been peer-reviewed. Any opinions or recommendations discussed are solely those of the author(s) and are not endorsed by BMJ. BMJ disclaims all liability and responsibility arising from any reliance placed on the content. Where the content includes any translated material, BMJ does not warrant the accuracy and reliability of the translations (including but not limited to local regulations, clinical guidelines, terminology, drug names and drug dosages), and is not responsible for any error and/or omissions arising from translation and adaptation or otherwise.

Open access This is an open access article distributed in accordance with the Creative Commons Attribution Non Commercial (CC BY-NC 4.0) license, which permits others to distribute, remix, adapt, build upon this work non-commercially, and license their derivative works on different terms, provided the original work is properly cited, appropriate credit is given, any changes made indicated, and the use is non-commercial. See: http://creativecommons.org/licenses/by-nc/4.0/.

ORCID iD

Yun Qian http://orcid.org/0000-0002-7921-6407

\section{REFERENCES}

1 Stumvoll M, Goldstein BJ, van Haeften TW. Type 2 diabetes: principles of pathogenesis and therapy. Lancet 2005;365:1333-46.

2 The International Diabetes Federation. Available: http://www. diabetesatlas.org/

$3 \mathrm{Xu}$ Y, Wang L, He J, et al. Prevalence and control of diabetes in Chinese adults. JAMA 2013;310:948-59.

4 Al-Daghri NM, Al-Attas OS, Alokail MS, et al. Diabetes mellitus type 2 and other chronic non-communicable diseases in the central region, Saudi Arabia (Riyadh cohort 2): a decade of an epidemic. BMC Med 2011;9:76.

5 Hossain P, Kawar B, El Nahas M. Obesity and diabetes in the developing world--a growing challenge. N Engl J Med 2007;356:213-5.

6 Wilson PWF, Meigs JB, Sullivan L, et al. Prediction of incident diabetes mellitus in middle-aged adults: the Framingham offspring study. Arch Intern Med 2007;167:1068-74.

7 Almgren P, Lehtovirta M, Isomaa B, et al. Heritability and familiality of type 2 diabetes and related quantitative traits in the Botnia study. Diabetologia 2011;54:2811-9.

8 Diabetes Genetics Initiative of Broad Institute of Harvard and MIT, Lund University, and Novartis Institutes of BioMedical Research, Saxena R, Voight BF, et al. Genome-Wide association analysis identifies loci for type 2 diabetes and triglyceride levels. Science 2007;316:1331-6.

9 Zeggini E, Weedon MN, Lindgren CM, et al. Replication of genomewide association signals in UK samples reveals risk loci for type 2 diabetes. Science 2007;316:1336-41.

10 Scott LJ, Mohlke KL, Bonnycastle LL, et al. A genome-wide association study of type 2 diabetes in Finns detects multiple susceptibility variants. Science $2007 ; 316: 1341-5$.

11 Sladek R, Rocheleau G, Rung J, et al. A genome-wide association study identifies novel risk loci for type 2 diabetes. Nature 2007;445:881-5.
12 Zeggini E, Scott LJ, Saxena R, et al. Meta-analysis of genome-wide association data and large-scale replication identifies additional susceptibility loci for type 2 diabetes. Nat Genet 2008;40:638-45.

13 Dupuis J, Langenberg C, Prokopenko I, et al. New genetic loci implicated in fasting glucose homeostasis and their impact on type 2 diabetes risk. Nat Genet 2010;42:105-16.

14 Voight BF, Scott LJ, Steinthorsdottir V, et al. Twelve type 2 diabetes susceptibility loci identified through large-scale association analysis. Nat Genet 2010;42:579-89.

15 Qian Y, Lu F, Dong M, et al. Cumulative effect and predictive value of genetic variants associated with type 2 diabetes in Han Chinese: a case-control study. PLoS One 2015:10:e0116537.

16 Liu J, Wang L, Qian Y, et al. Association of 48 type 2 diabetes susceptibility loci with fasting plasma glucose and lipid levels in Chinese Hans. Diabetes Res Clin Pract 2018;139:114-21.

17 Manolio TA, Collins FS, Cox NJ, et al. Finding the missing heritability of complex diseases. Nature 2009;461:747-53.

18 Maher B. Personal genomes: the case of the missing heritability. Nature 2008;456:18-21

19 Lu F, Qian Y, Li H, et al. Genetic variants on chromosome 6p21.1 and 6p22.3 are associated with type 2 diabetes risk: a case-control study in Han Chinese. J Hum Genet 2012;57:320-5.

20 Qian Y, Lu F, Dong M, et al. Genetic variants of IDE-KIF11-HHEX at 10q23.33 associated with type 2 diabetes risk: a fine-mapping study in Chinese population. PLoS One 2012;7:e35060.

21 Expert Committee on the Diagnosis and Classification of Diabetes Mellitus. Report of the expert Committee on the diagnosis and classification of diabetes mellitus. Diabetes Care 2000;23 Suppl 1:S4-19.

22 Lv X, Zhang L, Sun J, et al. Interaction between peroxisome proliferator-activated receptor gamma polymorphism and obesity on type 2 diabetes in a Chinese Han population. Diabetol Metab Syndr 2017:9:7.

23 Gong L, Li R, Ren W, et al. The FoxO1 Gene-Obesity interaction increases the risk of type 2 diabetes mellitus in a Chinese Han population. J Korean Med Sci 2017;32:264-71.

24 Li L, Wang J, Ping Z, et al. Interaction analysis of gene variants of TCF7L2 and body mass index and waist circumference on type 2 diabetes. Clin Nutr 2020;39:192-7.

$25 \mathrm{Li} \mathrm{H}$, Tang X, Liu Q, et al. Association between type 2 diabetes and rs10811661 polymorphism upstream of CDKN2A/B: a meta-analysis. Acta Diabetol 2013;50:657-62.

26 Grarup N, Rose CS, Andersson EA, et al. Studies of association of variants near the Hhex, CDKN2A/B, and IGF2BP2 genes with type 2 diabetes and impaired insulin release in 10,705 Danish subjects: validation and extension of genome-wide association studies. Diabetes 2007;56:3105-11.

27 Hribal ML, Presta I, Procopio T, et al. Glucose tolerance, insulin sensitivity and insulin release in European non-diabetic carriers of a polymorphism upstream of CDKN2A and CDKN2B. Diabetologia 2011;54:795-802.

28 't Hart LM, Simonis-Bik AM, Nijpels G, et al. Combined risk allele score of eight type 2 diabetes genes is associated with reduced first-phase glucose-stimulated insulin secretion during hyperglycemic clamps. Diabetes 2010;59:287-92.

29 Moritani M, Yamasaki S, Kagami M, et al. Hypoplasia of endocrine and exocrine pancreas in homozygous transgenic TGF-beta1. Mol Cell Endocrinol 2005;229:175-84.

30 Rane SG, Dubus P, Mettus RV, et al. Loss of CDK4 expression causes insulin-deficient diabetes and CDK4 activation results in beta-islet cell hyperplasia. Nat Genet 1999;22:44-52.

31 Kong Y, Sharma RB, Ly S, et al. CDKN2A/B T2D Genome-Wide Association Study Risk SNPs Impact Locus Gene Expression and Proliferation in Human Islets. Diabetes 2018;67:872-84.

32 Lillycrop K, Murray R, Cheong C, et al. Anril promoter DNA methylation: a perinatal marker for later adiposity. EBioMedicine 2017:19:60-72

33 Curtis EM, Murray R, Titcombe P, et al. Perinatal DNA methylation at CDKN2A is associated with offspring bone mass: findings from the Southampton women's survey. J Bone Miner Res 2017;32:2030-40.

34 Svensson P-A, Wahlstrand B, Olsson M, et al. Cdkn2B expression and subcutaneous adipose tissue expandability: possible influence of the 9p21 atherosclerosis locus. Biochem Biophys Res Commun 2014;446:1126-31.

35 Horswell SD, Fryer LGD, Hutchison CE, et al. Cdkn2B expression in adipose tissue of familial combined hyperlipidemia patients. $J$ Lipid Res 2013;54:3491-505.

36 Li P, Oh DY, Bandyopadhyay G, et al. Ltb4 promotes insulin resistance in obese mice by acting on macrophages, hepatocytes and myocytes. Nat Med 2015;21:239-47. 
37 Rankinen T, Kim SY, Pérusse L, et al. The prediction of abdominal visceral fat level from body composition and anthropometry: ROC analysis. Int J Obes Relat Metab Disord 1999;23:801-9.

38 Zhang X, Shu X-O, Gao Y-T, et al. General and abdominal adiposity and risk of stroke in Chinese women. Stroke 2009;40:1098-104.
39 Cheng $\mathrm{C}-\mathrm{H}$, Ho C-C, Yang C-F, et al. Waist-to-hip ratio is a better anthropometric index than body mass index for predicting the risk of type 2 diabetes in Taiwanese population. Nutr Res 2010;30:585-93.

$40 \mathrm{Hu} \mathrm{D}$, Xie J, Fu P, et al. Central rather than overall obesity is related to diabetes in the Chinese population: the InterASIA study. Obesity 2007;15:2809-16. 